\title{
Photoperiod Impact on a Sailor's Sleep-Wake Rhythm and Core Body Temperature in Polar Environment
}

\author{
Kévin de Blasiis, $\mathrm{MSc}^{1}$; Benoit Mauvieux, $\mathrm{PhD}^{2,3}$; Charlotte Elsworth-Edelsten, $\mathrm{PhD}^{4}$; Thierry Pezé, $\mathrm{PhD}^{5}$; \\ Romain Jouffroy, $\mathrm{PhD}^{6}$; Rémy Hurdiel, $\mathrm{PhD}^{5}$ \\ ${ }^{1}$ Sport, Health, Society Pluridisciplinary Research Unit (EA 7369), University Lille 2, Lille, France; ${ }^{2}$ French Institute of Health and Medical Research \\ (U1075 COMETE), Normandy University, Caen, France; ${ }^{3}$ Chronobiology Unit, Adolphe de Rothschild Foundation, Paris, France; ${ }^{4}$ School of Human \\ and Life Sciences, Canterbury Christ Church University, Canterbury, United Kingdom; ${ }^{5}$ Sport, Health, Society Pluridisciplinary Research Unit (EA \\ 7369), University of the Littoral Opale Coast, Dunkerque, France; ${ }^{6}$ Resuscitation Service (SAMU 75), Necker Hospital-Sick Children, Paris, France
}

\begin{abstract}
Introduction-Studies have reported circadian desynchronizations and sleep disruptions in onshore populations in the Arctic during the polar day. Although the Arctic region is becoming more accessible by sea and evidence is growing to implicate the importance of fatigue in sailing accidents, no study related to circadian disruptions has focused on sailors. The aim of this study was to observe, during a 155-d polar sailing trip between Greenland and Russia, the evolution of the sleep-wake rhythm and core body temperature $\left(\mathrm{T}_{\mathrm{c}}\right)$ in a sailor.

Methods - During the expedition, an electronic sleep diary was recorded daily and a continuous measurement of Tc using telemetric pills was performed every $10 \mathrm{~d}$ (recording depending on transit time, $\approx 24 \mathrm{~h}$ ). Ephemerides were manually determined day by day using global positioning system position and revealed 3 phases (phase 1: decrease of night duration; phase 2: polar day; phase 3: increase of night duration).

Results-A significant difference $(P<0.05)$ was observed in daily sleep time between phase $2(7.6 \pm 2.5$ $\mathrm{h}$ ) and phase $3(8 \pm 2 \mathrm{~h})$. The period of $\mathrm{T}_{\mathrm{c}}$ rhythm changed during the expedition (phase 1: $24.2 \pm 0.5 \mathrm{~h}$; phase 2: $25 \pm 0.3 \mathrm{~h}$; phase 3: $24 \pm 0.6 \mathrm{~h}$ ). Dissociation between Tc rhythm and sleep occurred during phase 2 .

Conclusions - Our study observed that during a polar sailing expedition, many circadian disruptions appeared as free-running rhythms or dissociation between sleep and Tc rhythm. Future studies will evaluate effects of these disruptions and their probable association with accident risks.
\end{abstract}

Keywords: Arctic, polar day, sailing trip, chronobiology, core temperature, sleep

\section{Introduction}

Polar regions represent natural laboratories for the observation of biological rhythms. ${ }^{1}$ Owing to the inclination of the Earth, these regions undergo significant yearly variations in day-night alternation. The Arctic is illuminated for several months (polar day) during the summer and is in complete darkness during winter (polar night). ${ }^{2}$

The light-dark cycle is the predominant environmental factor for the synchronization of the human biological clock to the 24-h cycle. In our physical environment, a day lasts $24 \mathrm{~h}$; to be in phase with it, external factors such as the light-dark cycle regulate the biological clock over a

Corresponding author: Kévin de Blasiis, MSc, 58 rue de la rivière, 72000 Le Mans, France.; e-mail: kevin.deblasiis@ gmail.com.

Submitted for publication July 2018.

Accepted for publication June 2019. period of $\approx 24 \mathrm{~h}$. Individuals deprived of environmental factors have a biological clock running throughout a period of $\approx 25 \mathrm{~h}$ (free run $)^{3-5}$ and are therefore not adapted to the 24-h period of a normal day. The unusual photoperiod, characterized by the total absence of moonlight during polar days, may increase risks of desynchronization and sleep disturbances. ${ }^{1,2,6-13}$

Core temperature $\left(\mathrm{T}_{\mathrm{c}}\right)$ seems to be a pertinent marker of the biological clock ${ }^{14,15}$ owing to its capacity to keep to a rhythm despite extreme environment or extreme physical activity. ${ }^{16,17} \mathrm{~T}_{\mathrm{c}}$ has a circadian rhythm (period of $\approx 24 \mathrm{~h}$ ) with a trough (bathyphase, which encourages sleep mechanisms) in the middle of the night and a peak (acrophase, which promotes wakefulness) at the end of the afternoon. Many studies have reported an evolution of Tc related to the sleep-wake rhythm, ${ }^{18-21}$ mostly by promoting melatonin production. Melatonin, referred to as the sleep hormone, has a circadian rhythm with an inverse relation to $T_{c}{ }^{22,23}$ 
(ie, with an acrophase in the middle of the night and a bathyphase in the end of the afternoon). Most studies in polar regions focus on this hormone $\mathrm{e}^{1,6-8,11,13}$ because its production is highly influenced by light. ${ }^{24-26}$ Indeed, light slows its secretion by blocking the key enzyme of its synthesis, $\mathrm{N}$-acetyltransferase. ${ }^{24}$ Studies have found a significant decrease in its production ${ }^{7}$ during expeditions in Antarctica and an important phase delay ${ }^{16}$ in polar days. Only 3 studies have focused on $\mathrm{T}_{\mathrm{c}}$ rhythmicity in the polar environment, ${ }^{1,16,27}$ and they also reported an important phase delay in polar days. Thus, Arctic or Antarctic regions particularly affect sleep. ${ }^{1,2,6-12}$ For example, out of 450 people living in northern Russia, $>80 \%$ reported sleep disturbances during times of extreme photoperiod. ${ }^{9}$ Regarding scientific expeditions, a reduction in sleep time and quality during an extreme photoperiod was observed. ${ }^{2,6-9}$

Since 1979, the Arctic ice area has reduced by $11 \%$ every $10 \mathrm{y}$, representing $>500,000 \mathrm{~km}^{2}$ per decade. ${ }^{28}$ Thus, in northern Canada, shipping traffic is constantly expanding, from around 100 trips in 2003 to $>350$ in $2013 .{ }^{29}$ However, currently, despite the growing accessibility of the polar regions by sea, ${ }^{30}$ studies have primarily included onshore populations. No study has focused on sailors' biological rhythms. With ice melting, navigation in polar areas requires increased vigilance for cold and icebergs. Seafarers must remain awake as long as possible to ensure correct navigation and the safety of their crew. Lifestyle on board is very different from onshore: Sailors must sleep using a polyphasic sleep method, which entails sleeping multiple times during their 24-h day. This mode of sleep does not alter sleep mechanisms, ${ }^{31,32}$ but the combination with extreme environments, such as polar regions, could lead to sleep impairments. In the past decade, reports on maritime accidents have suggested that the majority are related to human errors ${ }^{33}$ and that fatigue was one of the main reasons. ${ }^{34}$ Accidents at sea often result in loss of life or serious pollution. Despite considerable progress in regulations and technological advances (eg, satellite navigation, on-board computers, etc), sailing remains dangerous. ${ }^{35}$ Prolonged disturbance of biological rhythms and sleep for several weeks could negatively affect health ${ }^{24,36}$ or increase the risk of accidents. To improve safety of sailors in the future, it is necessary to study the impact of the polar day and polyphasic sleep on the sailor's biological clock. The aim of this case study was to observe the Tc rhythm as a circadian marker and the sleepwake rhythm of a seafarer during a 155-d polar sailing trip.

\section{Methods}

\section{PARTICIPANTS}

With approval from the ethics committee of the University Lille 2 of Health and Law, the study was conducted during a 155-d polar sailing trip between Sissimut (Greenland, $66^{\circ} 56^{\prime} 20^{\prime \prime} \mathrm{N} 53^{\circ} 40^{\prime} 20^{\prime \prime} \mathrm{W}$ ) and Petropavlovsk (Russia, $53^{\circ} 2^{\prime} 40^{\prime \prime} \mathrm{N}, 158^{\circ} 39^{\prime} 3^{\prime \prime} \mathrm{E}$; Figure 1). The participant was a 43 -y-old male sailor with $>20$ y of experience with an initial body mass index of $22.7 \mathrm{~kg} \cdot \mathrm{m}^{-2}(1.93 \mathrm{~m}, 82 \mathrm{~kg})$. His Chronotype Horne and Ostberg ${ }^{37}$ score indicated that he is neither a morning nor evening type.

He was responsible for navigation, repairs, and organization of life on the boat (Maewan IV, trisalu, $11.3 \mathrm{~m}$ long). He remained on board all the time and welcomed 14 people during the sailing trip in small groups for a few weeks. On board, the maximum number of people never exceeded 6 persons. During the protocol, he did not take any medication or receive instructions on his sleep.

An electronic sleep diary was recorded daily during the $14 \mathrm{~d}$ preceding departure and indicated a monophasic sleep cycle (a single phase of sleep per day) with a duration of $7.0 \pm 1.8 \mathrm{~h}($ mean $\pm \mathrm{SD})$. A continuous measurement, over $32 \mathrm{~h}$, of the subject's Tc using a telemetric capsule was performed $6 \mathrm{~d}$ before departure. This measurement showed a circadian rhythm $(\approx 24 \mathrm{~h})$ with an acrophase (peak rhythm) at 1617 and a bathyphase (trough rhythm) at 0347 . The midline estimating statistic of rhythm was $36.7^{\circ} \mathrm{C}$ and the amplitude was $0.8^{\circ} \mathrm{C}$.

\section{SLEEP-WAKE RHYTHM MEASUREMENT}

Polysomnography is a heavy and impractical method at sea, and boat movements can result in misleading actimetry readings. Because of this, a sleep diary was used to measure the sleep-wake rhythm. This is an effective tool for the evaluation of the subjective quality of sleep and for the characterization of the sleep-wake rhythm. ${ }^{38,39}$ An internet-based electronic version was specially designed for the experiment. Daily, after each sleep period, the sailor indicated his bedtime and waking time, scored quality of sleep between 1 and 10, and commented on quality.

A computer with various protections against polar conditions was installed aboard. The skipper could access the sleep diary daily during the $155 \mathrm{~d}$ of the trip.

\section{CORE TEMPERATURE MEASUREMENT}

Tc measurement was used because extreme conditions meant hormonal assays could not be performed during the sailing trip. It has been previously reported that Tc rhythm is related to the melatonin rhythm independent of polar conditions. ${ }^{1}$ To measure $\mathrm{T}_{\mathrm{c}}$, we used a Bodycap e-Celsius device (Caen, France). This consists of a capsule (17.9 $\mathrm{mm} \times 8.9 \mathrm{~mm}, 1.7 \mathrm{~g}$ ) that, after intake, transmits Tc values with a precision level of $\pm 0.2^{\circ} \mathrm{C}$ to a monitor every $30 \mathrm{~s}{ }^{40}$

During the $155 \mathrm{~d}$, a Tc measurement session was taken approximately every $10 \mathrm{~d}$, resulting in a total of 15 recording sessions (Table 1). For each measurement, only 


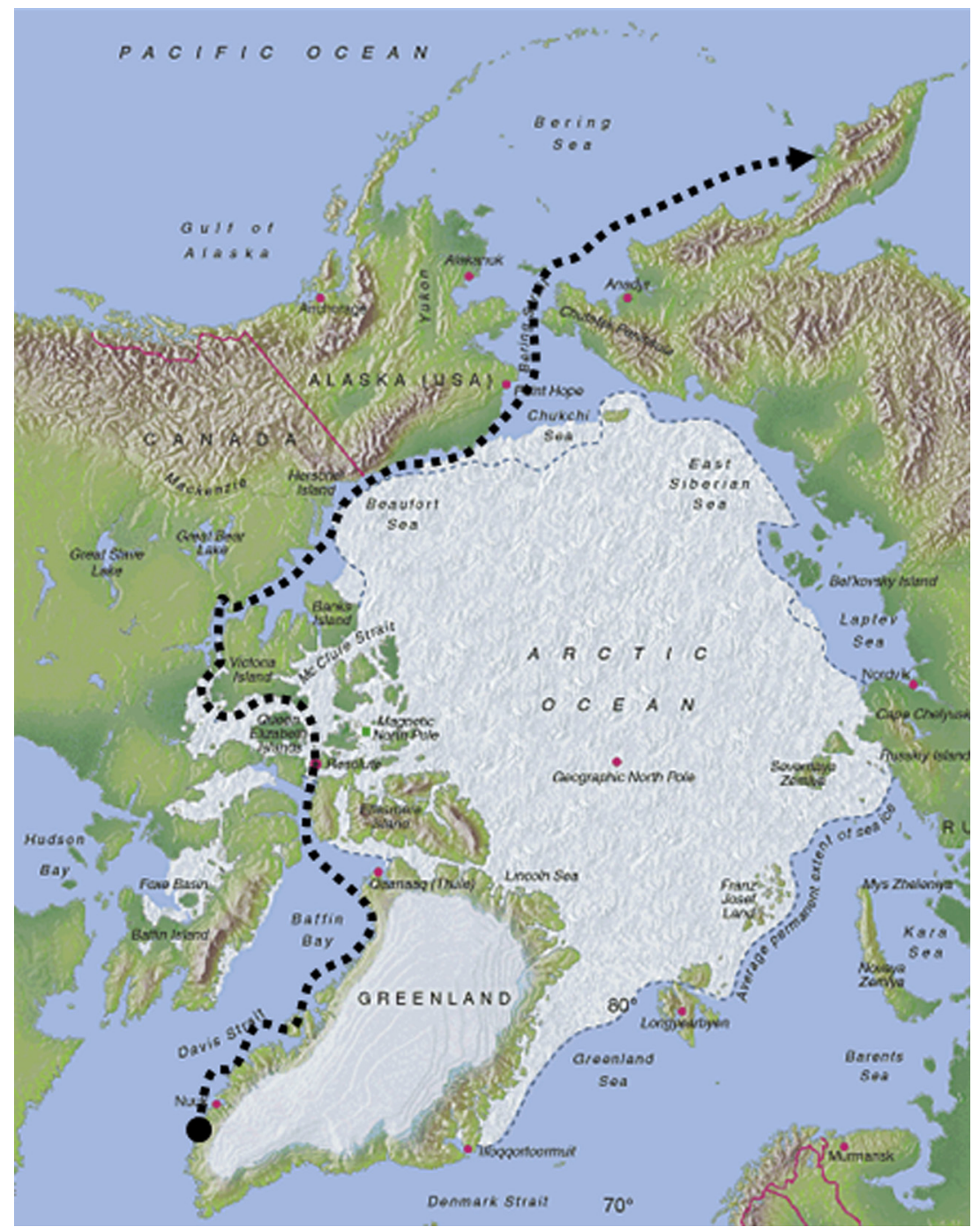

Figure 1. Mapping of the polar trip.

1 capsule was ingested. The session duration depends on intestinal transit time $(\approx 24 \mathrm{~h})$, with recording times ranging from 21 to $118 \mathrm{~h}$.

\section{PHOTOPERIOD MEASUREMENT}

Every day, the boat's position was calculated using a global positioning system (GPS) and Time Zero Navigator software (MaxSea, La Rochelle, France). Ephemerides were manually determined day by day after the experiment using the global positioning system coordinates and the National Oceanic and Atmospheric Administration application. The estimation of ephemerides reveals 3 distinct phases (Figure 2).

\section{STATISTICAL ANALYSIS}

The Lomb and Scargle test ${ }^{41}$ allowed the determination of $\mathrm{T}_{\mathrm{c}}$ rhythm for each recording session. Cosinor's model was applied to each $\mathrm{T}_{\mathrm{c}}$ recording session (ellipse test ${ }^{42}$ ), allowing the determination of the acrophase and bathyphase hours. For all $\mathrm{T}_{\mathrm{c}}$ measurement sessions $(\mathrm{n}=15)$, the daylight duration (per 24-h period) was calculated and the association between the bathyphase of $\mathrm{T}_{\mathrm{c}}$ and sleep was converted into a binary variable. We carried out a logistic regression analysis to verify the probability of a desynchronization between the $T_{c}$ rhythm and the wake-sleep rhythm as a function of the duration of the day. Significance was accepted at $P<0.05$. 
Table 1. Sailing day for each $\mathrm{T}_{\mathrm{c}}$ recording session

\begin{tabular}{|c|c|c|c|c|c|c|c|c|c|c|c|c|c|c|c|}
\hline Session & 1 & 2 & 3 & 4 & 5 & 6 & 7 & 8 & 9 & 10 & 11 & 12 & 13 & 14 & 15 \\
\hline Sailing day & 3 & 13 & 21 & 36 & 46 & 55 & 63 & 70 & 82 & 91 & 99 & 119 & 133 & 139 & 153 \\
\hline
\end{tabular}

$\mathrm{T}_{\mathrm{c}}$, core body temperature.

\section{Results}

\section{SLEEP-WAKE RHYTHM DURING THE EXPEDITION}

Sleep became polyphasic with $1.5 \pm 0.8$ sleep periods per day. The number of sleep periods per day varied among the different phases with $0.9 \pm 0.4$ during phase 1 , $1.5 \pm 0.8$ during phase 2 , and $1.7 \pm 0.8$ during phase 3 (Table 2). A significant difference existed between phase 1 and phase $3(P<0.01)$. No significant difference $(P=0.30)$ was observed between phase 2 and phase 3 . During phase 1, sometimes the skipper did not sleep, which can explain why the number of sleep periods per day is $<1$.

During the sailing trip, the daily duration of sleep was $7.4 \pm 2.5 \mathrm{~h}$ and did not significantly differ from the onshore sleep duration $(7 \pm 1.1 \mathrm{~h} ; P=0.14)$. The duration of sleep varied during the trip, from $7.3 \pm 01.3 \mathrm{~h}$ in phase 1 to $7.6 \pm 2.5 \mathrm{~h}$ in phase 2 and $8 \pm 1.9 \mathrm{~h}$ in phase 3 (Table 2). Significant differences between phase 1 and phase 3 $(P<0.01)$ and between phase 2 and phase $3(P<0.05)$ were observed.

\section{BODY CORE TEMPERATURE DURING SAILING}

The period of the $\mathrm{T}_{\mathrm{c}}$ rhythm varied during the trip, from $24.2 \pm 0.5 \mathrm{~h}$ during phase 1 (Table 2 ) to $25 \pm 0.3 \mathrm{~h}$ during phase 2 (Table 2) and $24.1 \pm 0.62 \mathrm{~h}$ during phase 3
(Table 2). A significant difference was observed in the period of the $\mathrm{T}_{\mathrm{c}}$ rhythm between phase 2 (polar day) and phase 3 (return of night; $P<0.05$ ).

During the polar day (phase 2), acrophase and bathyphase hours became irregular (Table 3, recording sessions 4 to 10). After darkness returned during phase 3 (Table 3 , recording sessions 11 to 15 ), bathyphase reappeared during the night and acrophase during the day.

The sleep diary underlined a wakefulness phase during each $T_{c}$ 's acrophase (Table 3, sessions 1 to 15 ), but a sleep phase in only $53 \%$ of bathyphase (Table 3 , sessions $4,5,6,7,8,10,11)$. Dissociation between bathyphase and sleep mainly occurred during polar day (Table 3, sessions $4,5,6,7,8,10)$. Logistic regression analysis showed a significant effect $(P=0.05)$ of the daylight duration on the association between $\mathrm{T}_{\mathrm{c}}$ bathyphase and sleep.

\section{Discussion}

In this study, we observed the sleep-wake rhythm and the $\mathrm{T}_{\mathrm{c}}$ rhythm of a sailor during a 155-d polar sailing trip. To our knowledge, no study has previously reported the evolution of circadian markers of a seafarer in this specific environment. We observed a lower sleep duration during the polar day $(7.6 \pm 2.5 \mathrm{~h})$ compared to the period when darkness returns $(8.0 \pm 1.9 \mathrm{~h} ; P<0.05)$. Regarding the $\mathrm{T}_{\mathrm{c}}$ rhythm, we observed that its period evolves as free-running

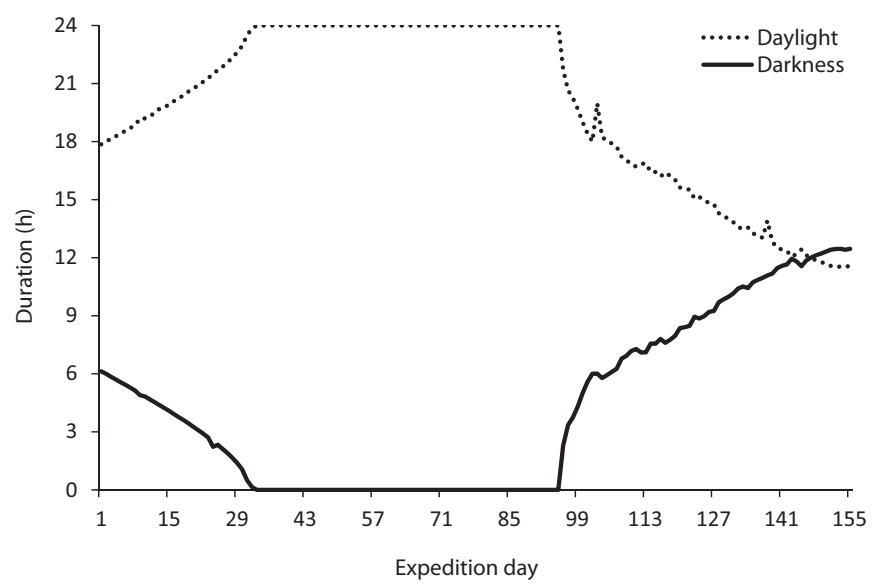

Figure 2. Evolution of the night and day durations during the sailing trip. Phase 1 (day 1 to day 32): phase during which the duration of the night decreased by $12 \pm 06 \mathrm{~min} \cdot \mathrm{d}^{-1}$. Phase 2 (day 33 to day 94 ): polar day phase. Phase 3 (day 95 to day 155): phase during which the duration of the night increased by $12 \pm 21 \mathrm{~min} \cdot \mathrm{d}^{-1}$. 
Table 2. Characteristics of sleep and $\mathrm{T}_{\mathrm{c}}$ rhythm according to the phase of the expedition

\begin{tabular}{llll}
\hline & Phase 1 & Phase 2 & Phase 3 \\
\hline Sleep period per day & $0.9 \pm 0.4^{b, c}$ & $1.6 \pm 0.8^{a}$ & $1.7 \pm 0.8^{a}$ \\
Daily sleep time (h) & $7.3 \pm 01.3^{b, c}$ & $7.5 \pm 2.5^{a, c}$ & $8.0 \pm 2.0^{a, b}$ \\
Period of $\mathrm{T}_{\mathrm{c}}$ rhythm (h) & $24.2 \pm 0.5^{b}$ & $25.0 \pm 0.3^{a, c}$ & $24.1 \pm 0.6^{b}$ \\
\hline
\end{tabular}

$\mathrm{T}_{\mathrm{c}}$, core body temperature.

${ }^{a}$ Significant difference $(P<0.05)$ from phase 1.

${ }^{b}$ Significant difference from phase 2 .

${ }^{c}$ Significant difference from phase 3 .

$(\approx 25 \mathrm{~h}$ ) during the polar day, meaning that it is no longer synchronized with the duration of the day, before being reframed to a normal period of $\approx 24 \mathrm{~h}$ when night returns (Table 2). Finally, dissociation between the sleep and $T_{c}$ bathyphase occurred also during the polar day (Table 3 ). All these results suggest that the variations of the daynight alteration may have disturbed the subject's circadian markers.

During sailing, constant attention is required, forcing sailors to adopt polyphasic sleep. ${ }^{31}$ According to the literature, such adaptation does not affect physical or cognitive performances, ${ }^{31,32}$ but the combination with polar day has not been studied yet. Here, we observed polyphasic sleep with an average of 1.5 periods of sleep per day. We observed a general increase in sleep periods during the trip, which is not really linked to the modifications of the light-dark cycle. No significant difference was found between the polar day in phase 2 and the return of darkness in phase 3. Based on these results it seems unlikely that photoperiod affected sleep periods. This increase could be explained by cumulative fatigue or an accumulated sleep debt, forcing the sailor to sleep more times a day.

The average sleep time recorded during sailing did not differ significantly from the recordings performed onshore. For comparison, the average sleep duration of the French population is $7.2 \mathrm{~h},{ }^{43}$ which is even less than our subject. The use of polyphasic sleep in polar sailing provides sleep times similar to that in the onshore population, which seems to be a good strategy.

As with the number of sleep periods, the daily sleep time increased during the expedition. As mentioned earlier, the Arctic and Antarctic regions have a significant impact on sleep time. ${ }^{1,2,6-13}$ Significant differences between polar day (phase 2) and phases with light-dark cycle (phases 1 and 3) indicate that our results suggest a similar trend, highlighting a possible involvement of the photoperiod in the regulation of sleep. ${ }^{6,25,26,44}$ We can assume that the polar day may have disrupted melatonin production, shortening the subjects sleep. This interpretation requires caution because we did not measure melatonin levels. Moreover, the daily sleep time was higher during the polar day than during the

Table 3. Association between the daylight duration, the hours of onset of $\mathrm{T}_{\mathrm{c}}$ bathyphase and acrophase, and the sleep-wake rhythm during the expedition

\begin{tabular}{|c|c|c|c|c|c|c|}
\hline $\begin{array}{l}T_{c} \text { recording } \\
\text { session }\end{array}$ & $\begin{array}{l}\text { Phase of } \\
\text { expedition }\end{array}$ & $\begin{array}{l}\text { Daylight } \\
\text { duration, } h\end{array}$ & $\begin{array}{l}T_{c} \text { bathyphase, } \\
24 \text { - } h \text { clock time }\end{array}$ & $\begin{array}{l}T_{c} \text { acrophase, } \\
24 \text { - } h \text { clock time }\end{array}$ & $\begin{array}{l}\text { Sleep during } T_{c} \\
\text { bathyphase }\end{array}$ & $\begin{array}{l}\text { Awakening during } \\
T_{c} \text { acrophase }\end{array}$ \\
\hline 1 & 1 & 18.3 & 0748 & 1921 & $\mathrm{Y}$ & Y \\
\hline 2 & 1 & 19.6 & 0827 & 2043 & $\mathrm{Y}$ & $\mathrm{Y}$ \\
\hline 3 & 1 & 21.5 & 0924 & 2056 & $\mathrm{Y}$ & $\mathrm{Y}$ \\
\hline 4 & 2 & 24.0 & 0910 & 2143 & $\mathrm{~N}$ & $\mathrm{Y}$ \\
\hline 5 & 2 & 24.0 & 1249 & 0114 & $\mathrm{~N}$ & $\mathrm{Y}$ \\
\hline 6 & 2 & 24.0 & 1726 & 0553 & $\mathrm{~N}$ & $\mathrm{Y}$ \\
\hline 7 & 2 & 24.0 & 0244 & 1453 & $\mathrm{~N}$ & $\mathrm{Y}$ \\
\hline 8 & 2 & 24.0 & 2052 & 0922 & $\mathrm{~N}$ & $\mathrm{Y}$ \\
\hline 9 & 2 & 24.0 & 0611 & 1834 & $\mathrm{Y}$ & $\mathrm{Y}$ \\
\hline 10 & 2 & 24.0 & 1322 & 0204 & $\mathrm{~N}$ & $\mathrm{Y}$ \\
\hline 11 & 3 & 19.7 & 1013 & 2231 & $\mathrm{~N}$ & $\mathrm{Y}$ \\
\hline 12 & 3 & 16.0 & 0630 & 1841 & $\mathrm{Y}$ & $\mathrm{Y}$ \\
\hline 13 & 3 & 13.5 & 0633 & 1754 & $\mathrm{Y}$ & $\mathrm{Y}$ \\
\hline 14 & 3 & 12.9 & 0547 & 1812 & $\mathrm{Y}$ & $\mathrm{Y}$ \\
\hline 15 & 3 & 11.5 & 0410 & 1558 & $\mathrm{Y}$ & $\mathrm{Y}$ \\
\hline
\end{tabular}

$\mathrm{T}_{\mathrm{c}}$, core body temperature. 
first phase, which is not related to the photoperiod and calls into question its involvement. The increase in daily sleep time could also be explained by cumulative fatigue or accumulated sleep debt and the subject's need to sleep longer. However, according to the sailor's comments, numerous repairs on the boat, a long preparation time, and many people on board (6 people) made navigation more difficult during phase 1 . This could explain the shorter daily sleep time and why the number of sleep periods was $<1$ per day.

Regarding Tc, many studies have reported an evolution related to the sleep-wake rhythm. ${ }^{18-21}$ In this study, we see that the acrophase was well associated with awakening for each recording, but the bathyphase was dissociated from sleep during polar day. Several previous studies have emphasized a relationship between melatonin production and thermoregulatory mechanisms. ${ }^{22,23}$ During an Arctic expedition, scientists observed an increase in blood melatonin level related to a decrease in rectal temperature. ${ }^{16} \mathrm{We}$ can assume that a possible decrease in melatonin production during the polar day may have disrupted thermoregulatory and sleep mechanisms. The related effect of the day duration on the sleep period $(P=0.05)$ could support this conclusion, but this interpretation is made with caution.

We observed that the longer the duration of the day, the more acrophase and bathyphase hours of $\mathrm{T}_{\mathrm{c}}$ become irregular (Table 3). After the return of light-dark cycle, acrophase and bathyphase gradually resynchronize. Biological rhythms are mainly regulated by endogenous factors, such as genetics, which give them a period of $\approx 25 \mathrm{~h}$. ${ }^{3}$ However, as explained in the introduction, in our physical environment a day lasts $24 \mathrm{~h}$ and to be in phase with it, external factors such as the light-dark cycle regulate the biological clock and synchronize circadian rhythms during a period of $\approx 24$ h. Individuals deprived of environmental factors will have a biological clock running over a period of $\approx 25 \mathrm{~h}$ (free run $)^{3-5}$ therefore not be adapted to the 24-h period of a normal day. In this study, the period of the $T_{c}$ rhythm tended to be in phase with photoperiod, with a free-running rhythm during polar day and a resynchronization on a 24-h period during other phases. These results are similar to those of previous studies in onshore populations. ${ }^{11-13}$ During an Antarctic expedition, scientists found circadian rhythms (melatonin, sleep, cortisol) evolving in free-running rhythm during the polar day before resynchronizing on a 24-h rhythm after the reappearance of darkness. ${ }^{13}$ Thus, the light-dark cycle seems to be an important synchronizer for our subject in the present study.

\section{LIMITATIONS}

Several limitations should be considered. First, this is a case study, and it is difficult to draw conclusion with only 1 subject. Second, because of the size of the boat and the extreme conditions in the Arctic, we were not able to stay with the subject during the protocol. For this reason some of our measures, such as $T_{c}$ measurement, were not standardized. The use of polysomnography or actigraphy was not possible on a daily basis at sea. It was necessary to use a sleep diary, which is a subjective method. It would have been interesting to obtain melatonin samples and measure light intensity to provide a more complete analysis and compare our results with other studies. During the expedition, the subject welcomed 14 other people (in small groups). It would have been interesting to also obtain information about social activity and life on board (work, nutrition, meal hours) because these factors could have affected the sleep time and circadian rhythms of our seafarer. Finally, information about fatigue, sleep loss, poor maneuvering, or poor operation would have allowed us to investigate the impact of circadian disorders on accident risks.

\section{Conclusions}

We report that during a polar sailing expedition, many circadian disruptions appeared in our sailor subject as freerunning rhythms or dissociation between sleep and $T_{c}$ rhythm during extreme photoperiod. We believe we are the first to investigate circadian desynchronizations in a sailor in this kind of environment. Because of the increasing number of polar sailing trips and the implication of human errors and fatigue in the majority of sea accidents, particular attention should be paid to circadian impairments, which could be dangerous for the health and safety of the crew ${ }^{24,36}$ by affecting sleep impairments and cognitive abilities. ${ }^{45-47}$ Future studies should focus on evaluating the effects of circadian desynchronizations, relations with accident risks, and strategies to better manage them.

Acknowledgment: We thank the Ultra Sport Science Foundation for their support.

Author Contributions: Study concept and design, RH; obtaining funding, $\mathrm{RH}$; acquisition of the data, $\mathrm{RH}$; analysis of the data, $\mathrm{KdB}, \mathrm{BM}$, $\mathrm{TP}, \mathrm{RH}$; drafting the manuscript, $\mathrm{KdB}, \mathrm{BM}, \mathrm{TP}, \mathrm{RH}, \mathrm{RJ}, \mathrm{CE}$; critical revision of the manuscript, $\mathrm{KdB}, \mathrm{BM}, \mathrm{TP}, \mathrm{RH}, \mathrm{CE}$; approval of final manuscript, $\mathrm{KdB}, \mathrm{BM}, \mathrm{TP}, \mathrm{RH}, \mathrm{RJ}, \mathrm{CE}$.

Financial/Material Support: This study was funded by Mobility as part of the Improve Your Way program.

Disclosures: None.

\section{References}

1. Yoneyama S, Hashimoto S, Honma K. Seasonal changes of human rhythms in Antarctica. Am J Physiol. 1999;277(4): 1091-7.

2. Skre IB, Hansen V, Braaten T, Lund E. Subjective sleeping and self-reported sleep length during four seasons in arctic northern Norway. Sleep Biol Rhythms. 2011;9:396. 
3. Aschoff J. Circadian rhythms in man. A self-sustained oscillator with an inherent frequency underlies human 24-h periodicity. Science. 1965;148:1428-32.

4. Siffre M, Reinberg A, Halberg F. L'isolement souterrain prolongé. Étude de deux sujets adultes sains avant, pendant et après cet isolement. Presse Med. 1966;74:915-9.

5. Siffre M, Chouvet G, Mouret J, Coindet J, Jouvet M. Périodicité bicircadienne du cycle veille-sommeil dans des conditions hors du temps. Etude polygraphique. Clin Neurophysiol. 1974;37(4):367-80.

6. Steinach M, Kohlberg E, Maggioni MA, Mendt S, Opatz O, Stahn A, et al. Sleep quality changes during overwintering at the German Antarctic stations Neumayer II and III: the gender factor. PLoS One. 2016;211(2):e0150099.

7. Chen N, Wu Q, Xiong Y, Chen G, Song D, Xu C. Circadian rhythm and sleep during prolonged Antarctic residence at Chinese Zhongshan Station. Wilderness Environ Med. 2016;27(4):458-67.

8. Pattyn N, Mairesse O, Cortoos A, Marcoen N, Neyt X, Meeusen R. Sleep during Antarctic summer expedition: new light on "polar insomnia.". Appl Physiol. 2017;122: 788-7.

9. Husby R, Lingjaerde O. Prevalence of reported sleeplessness in northern Norway in relation to sex, age and season. Acta Psychiatr Scand. 1990;81:542-7.

10. Bhattacharyya M, Pal MS, Sharma YK, Majumdar D. Changes in sleep patterns during prolonged stays in Antarctica. Int J Biometeorol. 2008;52(8):869-79.

11. Jonhson A, Engelmann W, Klemke W, Ekse AT. Free-running circadian rhythms in Svalbard. Z Naturforsch C Biosci. 1979;34(5-6):470-3.

12. Steel GD, Callaway M, Suedfeld P, Palinkas LA. Human sleep-wake cycles in the high Arctic: effects of unusual photoperiodicity in a natural setting. Bio Rhythm Res. 1995;26(5): 582-92.

13. Kennaway DJ, Van Dorp CF. Free-running rhythms of melatonin, cortisol, electrolytes, and sleep in humans in Antarctica. Am J Phys. 1991;260:1137-44.

14. Waterhouse J, Weinert D, Minors D, Folkard S, Owens D, Atkinson G, et al. Estimates of the daily phase and amplitude of the endogenous component of the circadian rhythm of core temperature in sedentary humans living nychthemerally. Biol Rhythm Res. 2000;31(1):88-107.

15. Koumar O. Modulation circadienne des mécanismes de thermorégulation et de l'alternance activité-repos sous l'influence de l'activité physique aiguë. Approche expérimentale et méthodologique. PhD Thesis. France: University of Caen Basse Normandie; 2005.

16. Pääkkönen T, Leppäluoto J, Palinkas LA, et al. Seasonal levels of melatonin, thyroid hormones, mood, and cognition near the Arctic circle. Aviat Space Environ Med. 2008;79: 695-9.

17. Callard D, Davenne D, Lagarde C, Gentil J, Van Hoecke. Nycthemeral variations in core temperature and heart rate: continuous cycling exercise versus continuous rest. Am J Sports Med. 2001;22(8):553-7.
18. Geschickter EH, Andrews PA, Bullard RW. Nocturnal body temperature regulation in man: a rationale for sweating in sleep. J Appl Physiol. 1966;21:623-30.

19. Campbell SS, Broughton RJ. Rapid decline in body temperature before sleep. Chronobiol Int. 1994;11:126-31.

20. Kräuchi K. How is the circadian rhythm of core body temperature regulated? Clin Auton Res. 2002;12:147-9.

21. Van Someren JW. More than a marker: interaction between the circadian regulation of temperature and sleep, age-related. Sleep Med. 2009;3(5):519-28.

22. Kraüchi K, Wirz-Justice A. Melatonin, thermoregulation and sleep onset latency. Neuropsychopharmacology. 2002;25(5): 92-6.

23. Kraüchi K, Cajochen C, Pache M, Flammer J, Wirz-Justice A. Thermoregulatory effects of melatonin in relation to sleepiness. Chronobiol Int. 2006;23(1-2):475-84.

24. Touitou Y. Désynchronisation de l'horloge interne: des conséquences en santé publique. Rev Prat. 2016;66:534-8.

25. Touitou Y, Reinberg A, Touitou D. Association between light at night, melatonin secretion, sleep deprivation, and the internal clock: health impacts and mechanisms of circadian disruption. Life Sci. 2017;173(2017):94-106.

26. Zhdanova I, Tucci V. Melatonin, circadian rhythms, and sleep. Curr Treat Options Neurol. 2003;5:225-9.

27. Tikhomirov II, Gunderson EKE. In: Edholm OG, ed. On the character of the daily rhythm of body temperature of the subjects at Vostok station. SCAR/IUPS/IUBS Symposium on Human Biology and Medicine in the Arntarctic. Heinemann; 1973:315-6.

28. Kattsov V, Ryabinin V, Overland JE, et al. Arctic sea-ice change: a grand challenge of climate science. J Glaciol Geocryol. 2010;56(200):1115-21.

29. Leach K, Reinhart J, Kepkay M, Kooka K, Miller M, Nappert MS. Report of the commissioner of the environment and sustainable development. In: Marine Navigation in the Canadian Arctic. Ottawa: Office of the Auditor General of Canada; 2014.

30. Zellen BS. Cold front rising: as global warming melts polar ice pack, a new race for the Arctic's resources begins. Strategic Insights, 2(8). Changes and treatment possibilities. Chronobiol Int. 2008;17:313-54.

31. Stampi C. Polyphasic sleep strategies improve prolonged sustained performance: a field study on 99 sailors. Work Stress. 1989;3(1):41-55.

32. Rak M, Kunath N, Breitenstein B, Pawlowski M, Steiger A, Dresler M. Endocrine and cognitive effects of a radically polyphasic sleep schedule. Pharmacopsychiatry. 2013;46(06).

33. Donaldson J, Rendle J, McIntyre A. Safer Ships, Cleaner Seas Report of Lord Donaldson's Enquiry into the Prevention of Pollution from Merchant Shipping. London: The Stationery Office Book, Edition HMSO; 1994.

34. Burke A, Ellis N, Allen P. The impact of work patterns on stress and fatigue among offshore worker populations. In: Contemporary Ergonomics. London: Taylor \& Francis; 2003:131-6. 
35. Tirilly G. Ajustement du rythme veille-sommeil et de la vigilance aux horaires fractionnés en mer: influence des facteurs circadiens et sociaux. $\mathrm{PhD}$ thesis. France: University of Toulouse; 2002.

36. Reutrakul S, Knutson KL. Consequences of circadian disruption on cardiometabolic health. Sleep Med Clin. 2015;10(4): 455-68.

37. Horne JA, Östberg O. A self-assessment questionnaire to determine morningness-eveningness in human circadian rhythms. Chronobiol Int. 1976;4:97-110.

38. Carskadon M, Dement W, Mitler M, Guilleminault C, Zarcone V, Spiegel R. Self-reports versus sleep laboratory findings in 122 drug-free subjects with complaints of chronic insomnia. Am J Psychiatry. 1976;133(12): 1382-8.

39. Espie C, Lindsay W, Espie L. Use of the sleep assessment device (Kelley and Lichstein, 1980) to validate insomniac's self-report of sleep pattern. Psychopathol Behav Asses. 1989;11(1):71-9.

40. Chapon P, Gauthier A, Bulla J, Moussais S. Calibration and performance assessment of a temperature sensor prototype using a 1-point calibration procedure. Rev Sci Instrum. 2012;83(11):114907.
41. Scargle J. Studies in astronomical time series analysis. II. Statistical aspects of spectral analysis of unevenly spaced data. Astrophys J. 1982;263:835-53.

42. Gouthière L, Claustrat B, Brun J, Mauvieux B. Complementary methodological steps in the analysis of rhythms: search of periods, modelling. Examples of plasma melatonin and temperature curves. Pathol Biol. 2005;53(5):285-9.

43. Beck F, Richard JB, Léger D. Prévalence et facteurs sociodémographiques associés à l'insomnie et au temps de sommeil en France (15-85 ans). Rev Neurobiol. 2013;169(12): 956-64.

44. Haffen E. Mesure des rythmes circadiens. L'encéphale. 2009;(2):63-7.

45. Banks S, Dinges D. Behavioral and physiological consequences of sleep restriction. J Clin Sleep Med. 2007;3(5): 519-28.

46. Van Dongen HPA, Hursh SR. Fatigue, Performance, Errors, and Accidents. In: Principles and Practice of Sleep Medicine. 5th Edition. Philadelphia: Elsevier Inc; 2010:753-9.

47. Whitney P, Hinson JM, Jackson ML, Van Dongen HPA. Feedback blunting: total sleep deprivation impairs decision making that requires updating based on feedback. Sleep. 2015;38(5):745-54. 